\title{
A novel transient structure with phylogenetic implications found in ratite spermatids
}

Lizette du Plessis $^{1 *+}$ and John T Soley ${ }^{2+}$

\begin{abstract}
Background: A novel transient structure was observed in the spermatids of three ratite species using transmission electron microscopy.

Results: The structure first appeared at the circular manchette stage of sperm development, was most prominent during the longitudinal manchette phase and disappeared abruptly prior to spermiation. It was composed of regularly-spaced finger-like projections which were closely associated with the outer nuclear membrane, giving the nucleus a cogwheel-like appearance. The projections were approximately $30 \mathrm{~nm}$ long and $14 \mathrm{~nm}$ wide. Although a similar structure has been described in certain lizard and crocodile species, this is the first report of a similar structure in the developing spermatids of birds.
\end{abstract}

Conclusions: The potential value of non-traditional characters, such as spermiogenesis and sperm ultrastructure, as phylogenetic markers has recently been advocated. The morphologically unique structure found in ratite spermatids provides additional evidence of a possible phylogenetic link between the reptiles and birds. It also endorses the basal positioning of the ratites as a monophyletic group within the avian phylogenetic tree.

Keywords: Ratites, Spermiogenesis, Phylogenetics

\section{Background}

Phylogenetic relationships, both within the class Aves and also between birds and reptiles, remain controversial. Morphological and molecular studies support the concept that the avian phylogenetic tree consists of two major nodes, namely the Palaeognathae, which include the orders Struthioniformes (ostrich, rhea, emu, cassowary, kiwi) and Tinamiformes (tinamous), and the Neognathae to which all other bird species belong [1,2]. Traditionally, the ratites and the tinamous are placed at the base of the avian phylogenetic tree and as such are considered to be the most "primitive" living birds [3-5]. This view has been supported by morphological data as well as by nuclear and mitochondrial DNA sequencing [6-10]. However, other studies using similar techniques have yielded contrasting evidence which suggests that the Passeriformes may in fact be the oldest lineage of modern birds [11-13]. This contradictory situation is further complicated by the

\footnotetext{
* Correspondence: lizette.duplessis@up.ac.za

${ }^{\dagger}$ Equal contributors

${ }^{1}$ Electron Microscope Unit, Department of Anatomy and Physiology, Faculty of Veterinary Science, University of Pretoria, Onderstepoort 0110, South Africa Full list of author information is available at the end of the article
}

observation that the method of data analysis can influence the allocation of phylogenetic relationships $[14,15]$.

Recently, the value of so-called non-traditional characters such as sperm ultrastructure and morphological aspects of spermiogenesis have been proposed as additional methods of indicating phylogenetic relationships [16-18]. Although spermiogenesis has been described in a variety of non-passerine bird species [19] including ratites [20-24], no morphological characters reflected during this process have, to date, been used to assist in assigning phylogenetic relationships.

This study describes the morphology of a unique, transient cytoplasmic structure that manifests during spermiogenesis in three ratite species, namely, the ostrich (Struthio camelus), rhea (Rhea americans albisceus) and emu (Dromaius novaehollandiae). The possible function of the structure and its significance as a non-traditional phylogenetic character are discussed.

\section{Methods}

The testes of 10 sexually mature and active emus (Dromaius novaehollandiae) and ostriches (Struthio camelus), respectively, were collected during the breeding season following

\section{Biomed Central}


slaughter at commercial abattoirs. Processed, resinembedded testes samples of a rhea (Rhea americans albisceus) were kindly supplied by Dr. David M. Phillips.

Small blocks of tissue were removed from the emu and ostrich testes and immediately fixed for 24 hours at $4^{\circ} \mathrm{C}$ in $4 \%$ glutaraldehyde buffered with $0.13 \mathrm{M}$ Millonig's phosphate buffer, $\mathrm{pH}$ 7.4. Samples were post-fixed for 1 hour in $1 \%$ similarly buffered osmium tetroxide and routinely prepared for transmission electron microscopy (TEM) $[24,25]$. Ultrathin sections were viewed in a Philips CM10 transmission electron microscope (Philips Electron Optical Division, Eindhoven, The Netherlands) operated at $80 \mathrm{kV}$. The resin samples of rhea testes had been fixed and processed as previously described [20] and were sectioned and stained as indicated above.

The linear dimensions of the individual projections forming the structure (length, width and distance between the projections) were determined using TEM images. A total of 45 projections was measured for each species. The measurements were processed using the Soft Imaging System iTEM software (Olympus, Münster, Germany) and expressed as the average \pm SD.

\section{Results and discussion}

Late-stage elongated spermatids in each of the three ratite species were characterised by the presence of a longitudinal collection of microtubules, the longitudinal manchette, surrounding the nucleus. The nucleus itself was composed of a dense mass of condensed chromatin closely enveloped by the nuclear membrane. In these spermatids, the zone of cytoplasm between the manchette microtubules and the nuclear membrane was occupied by a continuous array of small, regularly-positioned, fingerlike projections which appeared to emanate from the cytoplasmic surface of the nuclear membrane. In transverse section the uniform and symmetrical arrangement of the projections and their close association with the nuclear membrane gave the nucleus a characteristic "cogwheellike" appearance (Figures 1 and 2). While individual microtubules of the manchette were frequently linked by short, filamentous connections, there were no obvious connections between the microtubules of the longitudinal manchette and the finger-like projections. The observed morphology of the collective projections varied with the plane of section. In true transverse (Figure 1) or longitudinal sections of developing spermatids (Figure 3a,b) the projections manifested as typical finger-like structures. In oblique sections they adopted the form of a hazy zone of moderately electron-dense material (Figure 1) or as an array with a distinct lattice pattern (Figure 3c). The projections were identical in appearance when viewed in transverse or longitudinal sections of developing spermatids. Since the projections were visible in all profiles at this particular stage of spermatid development, it was concluded that they covered the entire surface of the nucleus. On average, the projections measured $29.75 \pm 4.2 \mathrm{~nm}, 30.87 \pm 4.09 \mathrm{~nm}$ and $31.7 \pm 5.44 \mathrm{~nm}$ in length for the emu $(n=45)$, ostrich $(n=45)$ and rhea $(\mathrm{n}=45)$, respectively. The width of the projections (measured at the base close to the nuclear membrane) was $13.36 \pm 2.45 \mathrm{~nm}$ in the emu, $13.13 \pm 1.68 \mathrm{~nm}$ in the ostrich, and $14.68 \pm 2.61 \mathrm{~nm}$ in the rhea. The average distance between projections was $19.59 \pm 4.4 \mathrm{~nm}$ in the emu, $19.49 \pm 2.03 \mathrm{~nm}$ in the ostrich and $20.71 \pm 4.39 \mathrm{~nm}$ in the rhea. In more advanced late stage elongating spermatids, the array of projections was observed to disappear leaving only a zone of flocculant material between the nuclear membrane and the manchette microtubules. This transition was abrupt.

The presence of transient nuclear membrane-associated projections during spermiogenesis in ratites has not been reported in any other avian species. The corresponding zone of cytoplasm of all other non-passerine species

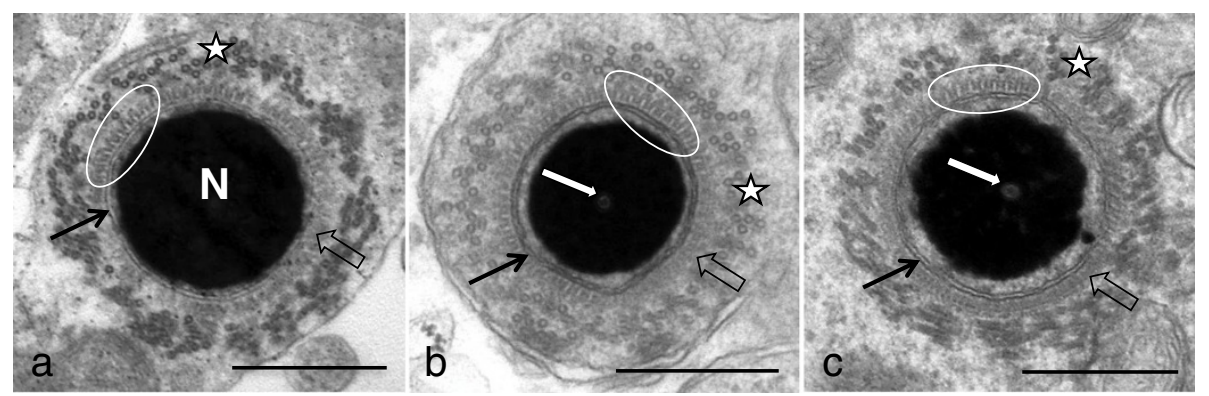

Figure 1 Transverse sections of late stage spermatids in (a) the emu, (b) ostrich and (c) rhea. Note the prominent longitudinal manchette microtubules (stars), the finger-like projections (encircled) closely associated with the outer nuclear membrane (black arrows) and the condensed chromatin of the nucleus (N). Individual manchette microtubules are closely aligned with, but not attached to, the finger-like projections. In some regions the projections appear as a fuzzy moderately electron-dense layer due to the plane of section (block arrows). The perforatorium typical of ostrich and rhea spermatids is visible within the nucleus (white arrows). Bar $=0.5 \mu \mathrm{m}$. 


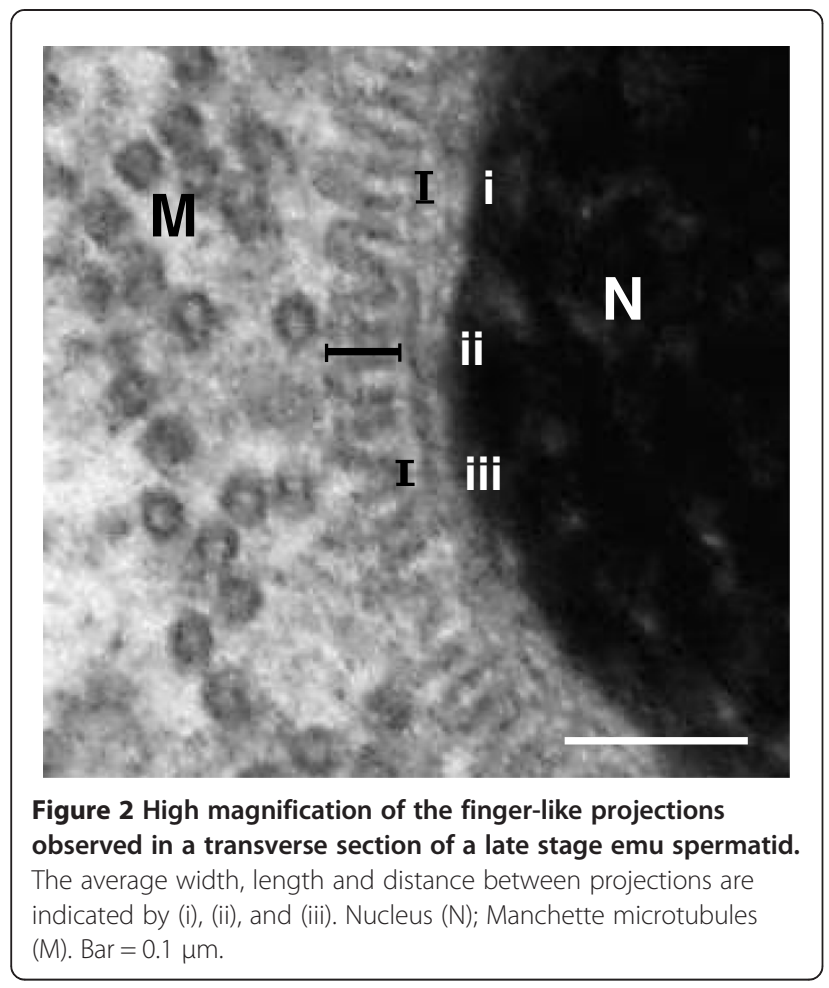

studied is occupied only by a layer of fine flocculant material $[20,21,24,26-36]$. The observed projections closely resemble structures previously reported in various lizard species [37-42] as well as in the Caiman (Caiman crocodiles) [43] and Nile crocodile (Crocodylus niloticus; personal observations). However, no morphological data other than the length of the "filaments" in the Caiman crocodile [43] have been presented. Based on TEM observations, the present study revealed that the projections were short, evenly spaced, peg- or finger-like extensions closely associated with the outer (cytoplasmic) face of the nuclear membrane. The projections were approximately $30 \mathrm{~nm}$ in length in the ratites compared to the $40 \mathrm{~nm}$ recorded in the Caiman crocodile [43]. Whether these observations point to inter-species variations, or simply reflect differences in technique and/or calibration of equipment, could not be determined. It is clear from this study that the nuclear membrane associated structure was not an artifact as it was present in all ratites examined $(n=21)$ despite differences in the preparation protocols $[20,24,25]$. Additionally, using the same technique, the structure was absent in closely related galliform and anseriform birds.

Various terms have been used to describe this transient structure. Examples include short filaments forming a "hairy headband" [43], radial projections or trabeculae associated with the nuclear membrane [37,40-42], bristles [44] and "saturations" originating from the nuclear envelope [38]. The use of these different and inconsistent terms accentuates the lack of detailed morphological information that is available. In lizards [37-42], and in both the Caiman [43] and Nile crocodiles, the projections appear to be restricted to the posterior aspect of the nucleus in the region just below the acrosome/nuclear shoulder, thus prompting the use of the term "hairy headband" [43]. In contrast, at the height of its development in the emu, ostrich and rhea, the projections were observed to cover the entire surface of the elongating spermatid nucleus, although they more obvious at the nuclear shoulder.

None of the earlier reports on reptiles provide evidence as to the possible nature of the "structure" other than to note the close connection of the projections with the cytoplasmic face of the nuclear membrane [37-39,41,42]. Similarly, its function remains enigmatic and its role during spermiogenesis is open to speculation. Ferreira and Dolder [42] were of the opinion that it connects the manchette microtubules to the nucleus, but failed to suggest a possible reason for such an association. Earlier reports noted
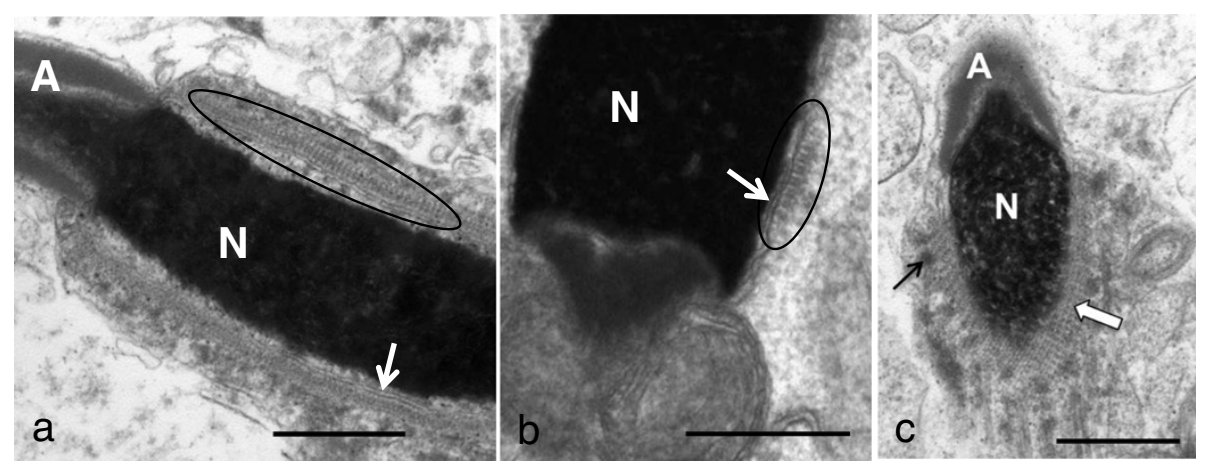

Figure 3 Longitudinal sections through (a) emu and (b) rhea spermatids. Note the prominence of the projections in the area immediately below the acrosome-nuclear shoulder in (a), but also at the base of the nucleus in (b) (encircled). (c) Oblique section of an emu spermatid demonstrating the typical lattice pattern (block arrow) formed by the projections. The nuclear chromatin $(\mathrm{N})$ is in the form of coarse granules, indicating an earlier stage of spermatid development than that illustrated in (a) and (b). A series of cytoplasmic densities is apparent in the vicinity of the manchette microtubules (black arrow). Acrosome (A), nuclear membrane (white arrows). Bar $=0.5 \mu \mathrm{m}$. 
a similar connection between the manchette microtubules and the "radial nuclear projections" [37,39], leading to the suggestion that they functioned together to anchor this region of the developing spermatid in order to facilitate tapering of the nucleus and its embedding within the surrounding Sertoli cell cytoplasm [39]. Al-Haji et al. [40] and Vieira et al. [41] also speculated that the projections anchor the manchette microtubules. Although the staggered arrangement of the longitudinal manchette placed a few individual microtubules close to the finger-like projections, no obvious morphological connection was observed between the two structures in ratites. No function has been ascribed to this "structure" in crocodiles [43].

Based on the parallel development of the "structure" and the manchette microtubules observed during spermiogenesis in the emu, ostrich and rhea, the proposed microtubule anchoring role of the projections is a plausible hypothesis. Classically, in mammals a sub-plasmalemmal density, the nuclear ring, forms posterior to the base of the acrosome from where the microtubules of the longitudinal manchette originate. The manchette has been widely implicated in mammals [45-50] and birds [24,26,27,29,32-34] in nuclear shaping/elongation and the caudal displacement of excess spermatid cytoplasm. Besides being anchored by the nuclear ring, a number of studies have identified linkers between individual microtubules of the manchette $[24,49,51]$ which presumably gives extra stability to the microtubular array. Russell et al. [49] also reported on the existence of linkers between the manchette and the nucleus in rodents and speculated that they served to maintain a defined position of the manchette in relation to the nucleus. It is tempting to suggest that a similar situation occurs in ratites, particularly as a nuclear ring is not present, and that the projections serve as the link between the nucleus and the manchette. Although the projections appear to emanate from the outer face of the nuclear membrane in ratites, no obvious morphological connection between them and the manchette microtubules has been observed. This is clearly illustrated at the base of the nucleus where the projections point away from the manchette microtubules. In ratites the projections cover the entire surface of the nucleus whereas in lizards and crocodiles they are limited to the nuclear surface immediately beneath the acrosome. If, as suggested for reptiles [42], a link exists between the nucleus and manchette via the projections, it would appear as if the projections in these species fulfill a similar role to that of the nuclear ring in mammals.

The distribution of the projections throughout the spermatid nucleus in ratites and their lack of obvious contact with the manchette microtubules may indicate an alternative role, namely that of nuclear stabilization. Elongation of the nucleus in ratites is striking in comparison to the situation in mammals and in these avian species it may be necessary to support or stabilize the relatively long and thin developing nucleus. In this capacity the projections would act as a form of scaffolding, particularly during the period of translocation of spermatid cytoplasm (longitudinal manchette stage) when they are maximally developed. The sudden disappearance of the projections at the height of nuclear elongation (head shaping and chromatin condensation completed) would support this proposed function. The scattered distribution of the projections in the form of small pockets during earlier stages of nuclear transformation may be necessary to ensure a degree of stability without sacrificing the flexibility required for morphological transformation. However, it is not clear why ratite spermatids would require nuclear scaffolding when it is absent in other non-passerine birds which display equally long nuclei, for example the chicken [30; personal observations] and duck [52; personal observations] and severely restricted in lizards [42] and crocodiles [43]. It could be argued that the nuclear membraneassociated projections seen in ratites and some reptilian species simply reflect a conserved character (symplesiomorphy) that is no longer of functional significance. An accurate determination of the composition of the projections would assist in answering this perplexing question.

Despite the lack of clarity on its function, the specific and organized nature of the transient "structure" revealed in the present study would appear to represent an important morphological character that can be applied for the resolution of phylogenetic questions as suggested by Gribbins [18]. Although not based on cladistic evidence, the observation that the only non-passerine birds with this unique structural adaptation studied to date appear to be the emu, ostrich and rhea, would support the traditional view that the extant ratites form a monophyletic group $[2,8,13,53-56]$. This view is strengthened by the fact that studies on galliform birds such as the chicken [26,28,30; personal observations], turkey [34], quail [32] and members of the anseriforms [33,57; personal observations], two families closely linked phylogenetically to the ratites, have failed to reveal an equivalent structure. It would be essential to determine whether the remaining members of the Ratidae (cassowaries and kiwis) also reflect the "structure" during spermiogenesis and indeed whether it is present in developing spermatids of the tinamous, as recent molecular studies have placed the tinamou together with the ratites as a polyphyletic group $[2,15,58,59]$.

The exclusive nature of the "structure" would also suggest that the ratites occupy a basal position in the avian phylogenetic tree as has been previously proposed $[3,7,10,13,60]$. The only other vertebrates reported to display this "structure" are the crocodiles [43] and certain lizard species [37-42,44]. This may be viewed as additional evidence that reptiles and birds share a common ancestor [7,11,61-64]. The birds, crocodiles and turtles are estimated to have branched from the 
Archosaurs approximately 272 million years ago (MYA), whereas lizards, together with snakes and the tuatara, derived from the Squamates approximately 230 MYA. As both the Archosaurs and Squamates evolved from early reptiles approximately 285 MYA [63], and as modern-day relatives of both groups share the transient structure, it is plausible that it represents an ancient character trait which has been conserved in certain extant species. Future studies on spermiogenesis in a wider variety of birds and reptiles may provide clarity in this respect.

There is further compelling evidence to support the basal positioning of the ratites outlined above. Comparative sequence analysis of the $\alpha$-crystallin A chain, a major constituent of the vertebrate eye lens, suggested that the ratites represent the first offshoot of the avian line with the crocodiles, represented by the alligator, as the sister group of the birds [60]. Similarly, mitochondrial protein sequencing [11], as well as amino acid sequencing and X-ray diffraction studies on the filament-matrix of $\beta$-keratins in emu feathers and scales of a lizard claw [64], supports the avian (ratite)/crocodile link. Various other anatomical/ morphological studies have also reinforced the close relationship between reptiles and birds $[10,61,62,65]$, including similarities in sperm structure [17]. Additionally, the morphological similarity between medullary bone of ratites and Tyrannosaurus rex points towards a close association between dinosaurs (an extinct member of the Archosaurs) and ratites [66].

\section{Conclusion}

It is proposed that the nuclear membrane-associated projections seen during spermiogenesis in ratites and certain reptiles represent an early reptilian feature reflected in members of both the Archosaurs and Squamates. Despite contrary reports on avian phylogeny proposing various other birds, notably the passerines, to be the oldest offshoot of the avian stem [12,14,67-69], the existence of this unique structure in ratites strengthens the argument that these birds form a monophyletic group with a basal position within the avian phylogenetic tree. Morphological characters expressed during spermiogenesis therefore form an important complementary tool for the resolution of phylogenetic questions.

\section{Abbreviation}

TEM: Transmission Electron Microscopy.

\section{Competing interests}

The authors declare no competing interests.

\section{Authors' contribution}

LdP and JTS designed the study; LdP prepared the emu samples and JTS the ostrich samples; LdP collected the data; LdP and JTS analysed and interpreted the results as well as jointly wrote the paper. All authors read and approved the final manuscript.

\section{Acknowledgements}

The authors wish to thank Dr David Phillips for providing the resinembedded blocks of rhea testicular material.

\section{Author details}

'Electron Microscope Unit, Department of Anatomy and Physiology, Faculty of Veterinary Science, University of Pretoria, Onderstepoort 0110, South Africa. ${ }^{2}$ Department of Anatomy and Physiology, Faculty of Veterinary Science, University of Pretoria, Onderstepoort 0110, South Africa.

Received: 14 March 2013 Accepted: 21 May 2013

Published: 26 May 2013

\section{References}

1. Ericson PGP: Current perspectives on the evolution of birds. Contrib Zool 2008, 77:109-116.

2. Hackett SJ, Kimbali RT, Reddy S, Bowie RCK, Braun EL, Braun MJ, Chojnowski JL, Cox WA, Han K, Harshman J, Huddleston CJ, Marks BD, Miglia KJ, Moore WS, Sheldon FH, Steadman DW, Witt CC, Yuri T: A phylogenomic study of birds reveals their evolutionary history. Science 2008, 320:1763-1768.

3. Cracraft J: The major clades of birds. In The Phylogeny and Classification of Tetrapods. Edited by Benton MJ. Oxford: Clarendon Press; 1988:339-361.

4. Cracraft J, Mindell DP: The early history of modern birds: A comparison of molecular and morphological evidence. In The hierarchy of life. Edited by Fernholm B, Bremer K, Jörnvall H. Amsterdam: Elsevier Science Publishers; 1989:389-403.

5. Leonard L, Dyke GJ, van Tuinen M: A new specimen of the fossil palaeognath Lithornis from the lower Eocene of Denmark. Am Mus Novit 2005, 3491:1-11.

6. Sibley CG, Ahlquist JE: The phylogeny and relationships of the ratite birds as indicated by DNA-DNA hybridization. In Evolution Today. Edited by Scudder GCE, Reveal JL. Pittsburgh: Hunt Institute for Botanical Documentation, Carnegie-Mellon University; 1981:301-335.

7. Sibley CG, Ahlquist JE: Phylogeny and classification of birds. New Haven: Yale University Press; 1995.

8. Sibley CG, Ahlquist JE, Monroe BL: A classification of the living birds of the world based on DNA-DNA hybridization studies. Auk 1988, 105:409-423.

9. Paton T, Haddrath O, Baker AJ: Complete mitochondrial DNA genome sequences show that modern birds are not descended from transitional shorebirds. Proc R SOC B 2002, 269:839-846.

10. García-Moreno J, Sorenson M, Mindell DP: Congruent avian phylogenies inferred from mitochondrial and nuclear DNA sequences. J Mol Evol 2003, 57:27-37.

11. Janke A, Arnason U: The complete mitochondrial genome of Alligator mississippiensis and the separation between recent Archosauria (birds and crocodiles). Mol Biol Evol 1997, 14:1266-1272.

12. Mindell DP, Sorenson MD, Dimcheff DE, Hasegawa M, Ast JC, Yuri T: Interordinal relationships of birds and other reptiles based on whole mitochondrial genomes. Syst Biol 1999, 48:138-152.

13. Van Tuinen M, Sibley CG, Hedges SB: The early history of modern birds inferred from DNA sequences of nuclear and mitochondrial ribosomal genes. Mol Biol Evol 2000, 17:451-457.

14. Braun EL, Kimball RT: Examining basal avian divergences with mitochondrial sequences: model complexity, taxon sampling, and sequence length. Syst Biol 2002, 51:614-625.

15. Haddrath O, Baker AJ: Multiple nuclear genes and retroposons support vicariance and dispersal of the paleaognaths, and an Early Cretaceous origin of modern birds. Proc R Soc Lond 2012, 279:4617-4625.

16. Koehler LD: Diversity of avian spermatozoa ultrastructure with emphasis on the members of the order Passeriformes. Memoir Mus Natl Hist 1995, 166:437-444.

17. Jamieson BMG: Avian spermatozoa: structure and phylogeny. In Reproductive Biology and Phylogeny of Birds Part A. Edited by Jamieson BMG. Jersey: Science Publishers; 2007:349-512.

18. Gribbins KM: Reptilian spermatogenesis: a histological and ultrastructural perspective. Spermatogenesis 2011, 1:250-269.

19. Aire TA: Spermatogenesis and testicular cycles. In Reproductive Biology and Phylogeny of Birds Part A. Edited by Jamieson BMG. Jersey: Science Publishers; 2007:279-348.

20. Phillips DM, Asa CS: Development of spermatozoa in the rhea. Anat Record 1989, 223:276-282. 
21. Baccetti $B$, Burrini $A G$, Falchetti E: Spermatozoa and relationships in Palaeognath birds. Biol Cell 1991, 71:209-216.

22. Soley JT: Centriole development and formation of the flagellum during spermiogenesis in the ostrich (Struthio camelus). J Anat 1994, 185:301-313.

23. Soley JT: Differentiation of the acrosomal complex in ostrich (Struthio camelus) spermatids. J Morphol 1996, 227:101-111.

24. Soley JT: Nuclear morphogenesis and the role of the manchette during spermiogenesis in the ostrich (Struthio camelus). J Anat 1997 190:563-576.

25. Du Plessis L, Soley JT: Abaxial tail implantation in the emu, Dromaius novaehollandiae: morphological characteristics and origin of a rare avian sperm defect. Theriogenology 2012, 77:1137-1143.

26. Nagano T: Observations on the fine structure of the developing spermatid in the domestic chicken. J Cell Biol 1962, 14:193-205.

27. McIntosh JR, Porter KR: Microtubules of the spermatids of the domestic fowl. J Cell Biol 1967, 35:153-173.

28. Tingari MD: Observations on the fine structure of spermatozoa in the testis and excurrent ducts of the male fowl, Gallus domesticus. J Reprod Fertil 1973, 34:255-265.

29. Okamura F, Nishiyama $\mathrm{H}$ : The early development of the tail and the transformation of the shape of the nucleus of the spermatid of the domestic fowl, Gallus gallus. Cell Tissue Res 1976, 169:345-359.

30. Gunawardana VK, Scott MGAD: Ultrastructural studies on the differentiation of spermatids in the domestic fowl. J Anat 1977, 124:741-755.

31. Sprando RL, Russell D: Spermiogenesis in the red-ear turtle (Pseudemys scripta) and the domestic fowl (Gallus domesticus): a study of cytoplasmic events including cell volume changes and cytoplasmic elimination. J Morphol 1988, 198:95-118.

32. Lin M, Jones RC: Spermiogenesis and spermiation in the Japanese quail (Coturnix coturnix japonica). J Anat 1993, 183:525-535.

33. Maretta M: Formation and role of the manchette microtubules in the poultry spermatids. Acta Vet Brno 1995, 64:23-29.

34. Aire TA: Ultrastructural study of spermiogenesis in the turkey, Meleagris gallopavo. Brit Poultry Sci 2003, 44:674-682.

35. Tripepi $\mathrm{S}$, Jamieson BGM, Brunelli E: Ultrastructure of the spermatid of Caprimulgus europaeus Linnaeus 1758, the European nightjar (Aves; Caprimulgidae), with phylogenetic implications. J Morphol 2006 267:1157-1164.

36. Lovas EM, Filippich LJ, Johnston SD: Spermiogenesis in the Australian cockatiel Nymphicus hollandicus. J Morphol 2012, 273:1291-1305.

37. Da Cruz-Landim C, Da Cruz-Höfling MA: Electron microscope study of lizard spermiogenesis in Tropidurus torquatus (Lacertilia). Caryologia 1977, 30:151-162.

38. Da Cruz-Höfling MA, Da Cruz-Landim C: The fine structure of nuclei during spermiogenesis in the lizard Tropidurus torquatus (Lacertilia). Cytologia 1978, 43:61-68.

39. Butler RD, Gabri MS: Structure and development of the sperm head in the lizard Podarcis (=Lacerata) taurica. J Ultrastruct Res 1984, 88:261-274.

40. Al-Hajj H, Janakat S, Mahmoud F: Electron microscopic study of sperm head differentiation in the lizard Agama stellio. Can J Zoolog 1987 65:2959-2968.

41. Vieira GHC, Wiederhecker HC, Colli GR, Báo SN: Spermiogenesis and testicular cycle of the lizard Tropidurus torquatus (Squamata, Tropiduridae) in the Cerrado of central Brazil. Amphibia-Reptilia 2001, 22:217-233.

42. Ferreira A, Dolder $\mathrm{H}$ : Sperm ultrastructure and spermiogenesis in the lizard, Tropidurus itambere. Biol Cell 2003, 27:353-362.

43. Saita A, Comazzi M, Perrotta E: Electron microscope study of spermiogenesis in Caiman crocodylus L. Ital J Zool 1987, 4:307-318.

44. Clark AW: Some aspects of spermiogenesis in a lizard. Am J Anat 1967, 121:369-400.

45. Phillips DM: Development of spermatozoa in the woolly opossum with special reference to the shaping of the sperm head. J Ultrastruct Res 1970, 33:369-380.

46. Phillips DM: Spermiogenesis. New York: Academic Press; 1974.

47. Myles DG, Hepler PK: Shaping of the sperm nucleus in Marsilea: A distinction between factors responsible for shape generation and shape determination. Dev Biol 1982, 90:238-252.

48. Barth AD, Oko RJ: Abnormal morphology of bovine spermatozoa. Ames: Iowa State University Press; 1989.
49. Russell LD, Russell JA, MacGregor GR, Meistrich ML: Linkage of manchette microtubules to the nuclear envelope and observations of the role of the manchette in nuclear shaping during spermiogenesis in rodents. Am J Anat 1991, 192:97-120.

50. Hermo L, Pelletier R-M, Cyr DG, Smith CE: Surfing the wave, cycle, life history, and genes/protein expressed by testicular germ cells. Part 2: Changes in spermatid organelles associated with development of spermatozoa. Micros Res Techniq 2010, 73:279-319.

51. MacKinnon EA, Abraham PJ, Svatek A: Long link induction between the microtubules of the manchette in intermediate stages of spermiogenesis. Z Zellforsch Mik Ana 1973, 136:447-460.

52. Maretta M: The ultrastructure of the spermatozoon of the drake. Acta Vet Brno 1975, 25:47-52

53. Cracraft J: Phylogeny and evolution of the Ratite birds. Ibis 1974 116:494-521.

54. Cracraft J: Avian evolution, Gondwana biogeography and the Cretaceous-Tertiary mass extinction event. Proc $R$ Soc Lond B 2001, 268:459-469.

55. Haddrath O, Baker AJ: Complete mitochondrial DNA genome sequences of extinct birds: Ratite phylogenetics and the vicariance biogeography hypothesis. Proc R Soc Lond B 2001, 268:939-945.

56. Johnston P: New morphological evidence supports congruent phylogenies and Gondwana vicariance for palaeognathous birds. Zool J Linn Soc-Lond 2011, 163:959-982.

57. Simões K, Orsi AM, Viegas KAS: Ultrastructural characteristics of spermiogenesis in the domestic duck (Anas platyrhynchos). Anat Histol Embryol 2005, 34:307-311.

58. Harshman J, Braun EL, Braun MJ, Huddleston CJ, Bowie RCK, Chojnowski JL, Hackett SJ, Han K-L, Kimball RT, Marks BD, Miglia KJ, Moore WS, Reddy S, Sheldon FH, Steadman DW, Steppan SJ, Witt CC, Yuri T: Phylogenetic evidence for multiple losses of flight in ratite birds. PNAS 2008, 105:13462-13467.

59. Smith JV, Braun EL, Kimball RT: Ratite nonmonophyly: independent evidence from 50 novel loci. Syst Biol 2013, 62:35-49.

60. Stapel SO, Leunissen JAM, Versteeg M, Wattel J, de Jong WW: Ratites as oldest offshoot of avian stem - evidence from a-crystallin A sequences. Nature 1984, 311:257-259.

61. Walker AD: New light on the origin of birds and crocodiles. Nature 1972, 237:257-266.

62. Whetstone KN, Martin LD: New look at the origin of birds and crocodiles. Nature 1979, 279:234-235.

63. Rest JS, Ast JC, Austin CC, Waddell PJ, Tibbetts EA, Hay JM, Mindell DP. Molecular systematics of primary reptilian lineages and the tuatara mitochondrial genome. Mol Phylogenet Evol 2003, 29:289-297.

64. Fraser RDB, Parry DAD: The structural basis of the filament-matrix texture in the avian/reptilian group of hard $\beta$-keratins. J Struct Bio/ 2011, 173:391-405.

65. Gower DJ, Weber E: The braincase of Euparkeria, and the evolutionary relationships of birds and crocodilians. Biol Rev 1998, 73:367-411.

66. Schweitzer MH, Wittmeyer JL, Horner JR: Gender-specific reproductive tissue in ratites and Tyrannosaurus rex. Science 2005, 308:1456-1460.

67. Feduccia A: Explosive evolution in tertiary birds and mammals. Science 1995, 267:637-638

68. Härlid A, Arnason U: Analyses of mitochondrial DNA nest ratite birds within the Neognathae: supporting a neotenous origin of ratite morphological characters. Proc R Soc Lond B 1999, 266:305-309.

69. Johnson KP: Taxon sampling and the phylogenetic position of Passeriformes: Evidence from 916 avian cytochrome b sequences. Syst Biol 2001, 50:128-136.

doi:10.1186/1471-2148-13-104

Cite this article as: du Plessis and Soley: A novel transient structure with phylogenetic implications found in ratite spermatids. BMC Evolutionary Biology 2013 13:104. 